\title{
Resistance of Venturia inaequalis to quinone outside inhibitor (QoI) fungicides in New Zealand apple orchards
}

\author{
S.L.H. Viljanen-Rollinson ${ }^{1}$, S.M. Thompson ${ }^{1}$, S. Keenan ${ }^{1}$, S.R. Bulman ${ }^{1}$, P.J. Wright ${ }^{2}$, \\ P.N. Wood ${ }^{3}$, N.M. Park ${ }^{3}$ and R.M. Beresford ${ }^{4}$ \\ ${ }^{1}$ The New Zealand Institute for Plant \& Food Research Limited, Private Bag 4704, \\ Christchurch, New Zealand \\ ${ }^{2}$ The New Zealand Institute for Plant \& Food Research Limited, Cronin Road, RD 1, \\ Pukekohe, New Zealand \\ ${ }^{3}$ The New Zealand Institute for Plant E Food Research Limited, Hawke's Bay Research \\ Centre, Private Bag 1401, Havelock North, Hastings 4157, New Zealand \\ ${ }^{4}$ The New Zealand Institute for Plant E Food Research Limited, Mt Albert Research \\ Centre, Private Bag 92169, Auckland 1142, New Zealand \\ Corresponding author: suvi.viljanen@plantandfood.co.nz
}

\begin{abstract}
DNA sequencing and optimisation of allele-specific primers targeting the G143A mutation, which confers resistance in Venturia inaequalis (apple black spot) to quinone outside inhibitor (QoI) fungicides, was used to develop a resistance testing method for orchard surveys. The method confirmed the resistance status of $15 \mathrm{~V}$. inaequalis isolates that were classified as sensitive or resistant to trifloxystrobin using a mycelial growth assay. Disease caused by four isolates carrying the G143A mutation was not controlled by the QoI fungicide trifloxystrobin in an inoculated potted tree experiment. In a survey of 41 apple orchards in Hawke's Bay, Nelson, Otago and Waikato during 2011-12 the G143A mutation occurred in $54 \%$ of $802 \mathrm{~V}$. inaequalis isolates, and $59 \%$ of orchards had more than $50 \%$ of isolates with the mutation present. The results indicate that orchards with a high G143A mutation frequency can be expected to experience loss of black spot control where QoI fungicides are used.
\end{abstract}

Keywords apple scab, fungicide resistance, Quinone outside Inhibitor, resistance management.

\section{INTRODUCTION}

Apple black spot, caused by Venturia inaequalis, is a serious disease of apples worldwide, including New Zealand. It is controlled by frequent use of fungicides belonging to several different groups, including quinone outside inhibitors or QoIs. QoI fungicides were first sold in 1996 and have since been widely used overseas and in New
Zealand to control various plant diseases. These fungicides all act at the quinone 'outside' (Qo) binding site of the cytochrome $b c 1$ complex. Because QoIs have a specific, single-site mode of action, there is a high risk of resistance development in $V$. inaequalis. QoI resistance is conferred by a number of single point mutations 
in the cytochrome $b$ gene, of which the mutation G143 is the most common and has the highest resistance factor (Gisi et al. 2002). Currently there are 37 pathogens with field resistance to QoI fungicides (Fungicide Resistance Action Committee 2013). In V. inaequalis, the G143A mutation has been reported in Europe (Küng Farber et al. 2002) and North America (Köller et al. 2004). The QoI fungicides, kresoximmethyl, trifloxystrobin and pyraclostrobin, have been used in New Zealand under a resistance management strategy that limits usage to a maximum of four applications per season and limits the number of consecutive applications to two (http://resistance.nzpps.org/).

After a severe black spot outbreak in 2009 in Nelson and Hawke's Bay, QoI resistance testing carried out in Germany showed the G143A mutation was present in some orchards (Fungicide Resistance Action Committee 2010). The project reported in this paper was initiated to develop a DNA-based resistance testing method because no method was available in New Zealand at that time for detecting the G143A mutation. It was subsequently used in a nationwide survey to determine how widespread QoI resistance was in New Zealand apple orchards. The method was developed using $V$. inaequalis isolates selected from a 2010-11 survey of Hawke's Bay apple orchards for dodine and demethylation inhibitor fungicide sensitivity (Beresford et al. 2012) and was then used to test isolates collected in a nationwide survey from orchards in Hawke's Bay, Nelson, Waikato and Otago in 2011-12.

\section{MATERIALS AND METHODS}

Two methods for detecting resistance of $V$. inaequalis to QoI fungicides were adapted from published information: (1) A mycelial growth assay in agar culture to determine the concentration of the QoI fungicide trifloxystrobin that inhibited growth by $50 \%\left(\mathrm{EC}_{50}\right)$ and (2) detection of the G143A mutation using the polymerase chain reaction (PCR). The ability of trifloxystrobin to control resistant $V$. inaequalis isolates, as classified by the mycelial growth assay and presence of the G143A mutation, was tested using a plant inoculation assay on potted apple trees.

\section{Mycelial growth assay for sensitivity to trifloxystrobin}

Fifteen $V$. inaequalis isolates from a Hawke's Bay survey during 2010-2011 (Beresford et al. 2012) were selected from either organic orchards with no synthetic fungicide use for at least 5 years or from Integrated Fruit Production (IFP) orchards with a history of high QoI use (Table 1). The QoI-sensitivity of 12 of these isolates was determined by comparing mycelial colony diameter on agar amended with trifloxystrobin (Twist ${ }^{\circledR}$ SC containing 500 g trifloxystrobin/litre) with that on non-amended agar. Amended plates were prepared by dissolving Twist ${ }^{\circledR}$ in sterilised water to obtain a stock solution (Michalecka et al. 2011). Measured amounts of stock solution were added to potato dextrose agar (PDA) $\left(55^{\circ} \mathrm{C}\right)$ to obtain final concentrations of $0,0.0001$, $0.001,0.01,0.05,0.1,1,10$ and 100 mglitre trifloxystrobin. Ampicillin $(500 \mu \mathrm{g} / \mathrm{ml})$, penicillin $(100 \mu \mathrm{g} / \mathrm{ml})$ and streptomycin $(100 \mu \mathrm{g} / \mathrm{ml})$ were added to all agar media (Chapman et al. 2011). An additional set of agar plates was prepared that included 100 mglitre salicylhydroxamic acid (SHAM) to inhibit the alternative oxidation pathway of sensitive isolates (Steinfeld et al. 2001, Köller et al. 2004). SHAM was dissolved in 1:1 (vol:vol) acetone:methanol and added into the cooled autoclaved agar. The concentration of SHAM was $100 \mathrm{mg} /$ litre (Jobin \& Carisse 2007). Each test plate was seeded with 6.5-mm diameter mycelial plugs of four $V$. inaequalis isolates cut from actively growing cultures. There were three replicate plates for each isolate. The plates were sealed and incubated in the dark at $20^{\circ} \mathrm{C}$. After 28 days of incubation, $\mathrm{EC}_{50}$ values were calculated from the mean of two colony diameter measurements (plug diameter deducted), as the concentration at which relative growth was $50 \%$ of the un-amended control, where relative growth was the mean diameter on each amended plate/ the mean diameter on the un-amended control.

\section{PCR test for the G143A mutation}

The protocol to extract genomic DNA from fungal isolates was adapted from Möller et al. (1992, M.D. Templeton, Plant \& Food Research, personal communication). Mycelia 
were scraped from the surface of the agar and transferred to an Eppendorf tube. The mycelia were ground in $500 \mu \mathrm{l}$ of TES (100 mM Tris, 10 $\mathrm{mM}$ ethylenediaminetetraacetic acid (EDTA), $2 \%$ sodium dodecyl sulphate (SDS), $\mathrm{pH} 8$ ) with a micropestle. One hundred and forty $\mu \mathrm{l}$ of $5 \mathrm{M}$ sodium chloride and $65 \mu \mathrm{l}$ of $10 \%$ cetyl trimethylammonium bromide were added to each sample and incubated for $10 \mathrm{~min}$ at $65^{\circ} \mathrm{C}$. Seven hundred and five $\mu$ l of chloroform:isoamyl alcohol $(24: 1 \mathrm{v} / \mathrm{v})$ was added, mixed by inversion and incubated on ice for $30 \mathrm{~min}$. After centrifuging for $10 \mathrm{~min}$ at $13,000 \mathrm{rpm}$, the aqueous phase was transferred to a new tube with $225 \mu$ of $5 \mathrm{M}$ ammonium acetate, then incubated on ice for 0.5-24 h. After centrifuging for $10 \mathrm{~min}$ at 13,000 $\mathrm{rpm}$, an equal volume of ice-cold isopropanol was added to the aqueous phase, then left on ice for at least $30 \mathrm{~min}$. The DNA was pelleted by centrifuging at $13000 \mathrm{rpm}$ for $10 \mathrm{~min}$. DNA was resuspended in $50 \mu \mathrm{l}$ of elution buffer $(10 \mathrm{mM}$ Tris, 1 mM EDTA).

The multiplex PCR assay described by Fontaine et al. (2009) was adapted and used to detect the G143A mutation in the cytochrome $b$ gene. Twenty-five $\mu \mathrm{l}$ reactions were prepared containing $1 \times$ Hot GoTaq mastermix (Promega) and up to $10 \mathrm{ng}$ of gDNA. After screening of the 2010-2011 samples, the control primer PR-exon7 was modified to PR-exon7a: 5'-CAAGAGGTACAATAATCACAAAGTGAG-3' based on sequences in GenBank. $200 \mathrm{nM}$ of G143AMM1 and PS1 and 100 nM of PS-exon7 and PR-exon7a were used per reaction. The reactions were amplified as described by Fontaine et al. (2009) on a BioRad T100 Thermal Cycler. Ten $\mu$ l of each PCR product was run on $1 \%$ agarose gels.

Samples for sequencing were amplified using Hot GoTaq Green mastermix, the primers (PS1/PR1), and cycling conditions described by Fontaine et al. (2009). The products were purified from agarose gels using a GeneAid gel extraction kit. Sequencing with PCR primers was carried out by Macrogen ${ }^{\circledR}$. DNA sequences were assembled, edited and aligned in Geneious (http://www.geneious.com/).

\section{Plant inoculation assay}

The ability of trifloxystrobin to control disease caused by isolates of $V$. inaequalis carrying the
G143A mutation was investigated on the leaves of 2-year-old potted 'Gala' apple trees. Before inoculation, a single spray application was made of either trifloxystrobin (Flint ${ }^{\circledR}, 500 \mathrm{~g} / \mathrm{kg}$ trifloxystrobin, at $0.1 \mathrm{~g} /$ litre) or water. Two hours after treatment, shoots were inoculated with five separate isolates classified as sensitive (S), because they did not carry the G143A mutation, and four separate isolates classified as resistant (R) that carried the G143A mutation (Table 1), using $1 \times 10^{5} \mathrm{~V}$. inaequalis conidia/ml of each isolate. Inoculated leaves were tagged for later identification. Apple plants that were noninoculated and non-fungicide-treated were used to check that background Venturia inaequalis infection was absent from the trees. Conidia for inoculation were produced from PDA cultures growing on a cellophane layer to promote sporulation. After inoculation, plants were incubated at high relative humidity in a plastic tent for $24 \mathrm{~h}$. Six replicate shoots were used for each treatment. After incubation, the trees were placed in a glasshouse for 25 days then visually assessed for percentage of leaf area covered by sporulating black spot on the inoculated leaves. Black spot development was expressed as relative disease severity, which was the mean severity (percentage leaf area with sporulating Venturia inaequalis) on trifloxystrobin-treated apple leaves as a percentage of the mean severity on water-sprayed leaves.

\section{Orchard survey, V. inaequalis isolation and fungicide use in the surveyed orchards}

Approximately $20 \mathrm{~V}$. inaequalis isolates per orchard were obtained during December 2011 and January 2012 from apple fruit lesions from 41 orchard blocks in Hawke's Bay (25), Nelson (7), Otago (4) and Waikato (5), as described in Beresford et al. (2013). The cultivars sampled were 'Royal Gala' (35), 'Braeburn' (2), 'Fuji' (2) and Pink Lady ${ }^{\circledR}(2)$. All but five of the orchards were managed under Pipfruit New Zealand's Integrated Fruit Production programme and five Hawke's Bay orchards (HB-05, HB-06 HB-07, HB-08 and HB-15) were managed under organic production. Venturia inaequalis conidia were scraped from the sporulating lesions and streaked onto water agar. After $48 \mathrm{~h}$ of incubation at $20^{\circ} \mathrm{C}$, individual 


\section{口 1-5 (sensitive ) $\Delta 4$-4 (resistant) • 9-9 (intermediate)}

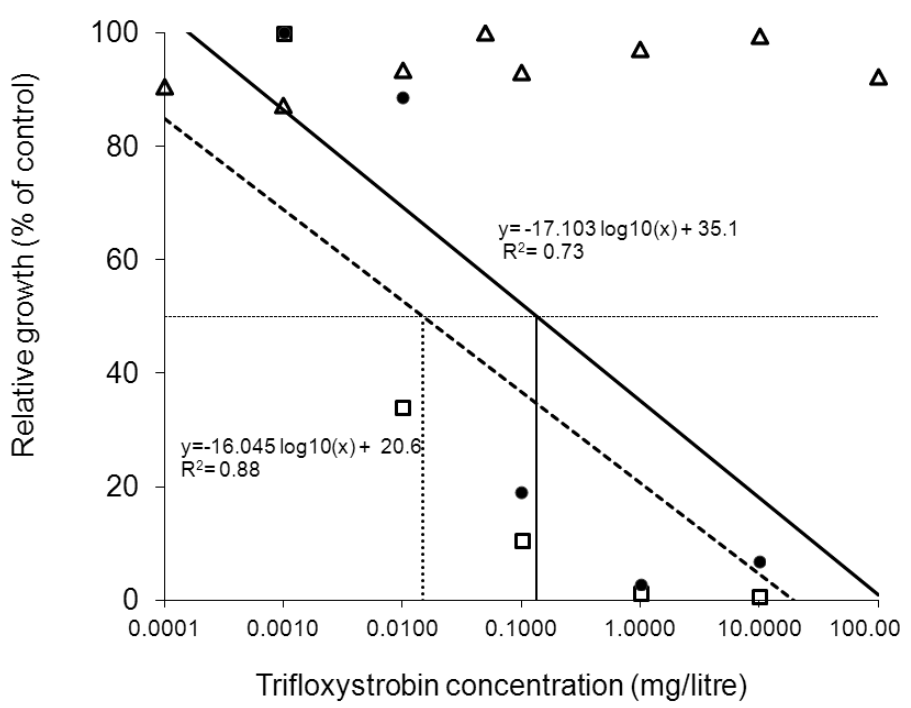

Figure 1 Determining the effective concentration of trifloxystrobin on amended agar that inhibited growth of Venturia inaequalis by $50 \%$ compared with the nonamended control $\left(\mathrm{EC}_{50}\right)$. The three example isolates shown are 1-5 ( $\mathrm{EC}_{50} 0.015 \mathrm{mg} /$ litre), which was typical of the sensitive isolates, 9-9 (EC $\mathrm{EC}_{50} 0.134 \mathrm{mg} /$ litre), which was a single isolate with intermediate sensitivity, and 4-4 $\left(\mathrm{EC}_{50}>100 \mathrm{mg} /\right.$ litre $)$, which was typical of the resistant isolates containing the G143A mutation. germinating conidia were isolated onto PDA amended with penicillin (100 mg/litre) and streptomycin sulphate $(100 \mathrm{mg} /$ litre $)$ to inhibit bacteria. Colonies were incubated on a laboratory bench at $18-20^{\circ} \mathrm{C}$ in natural light and were subcultured, if necessary, to eliminate contaminants. In total, 802 isolates from culture were tested for the presence or absence of the G143A mutation conferring resistance to QoI fungicides. From most orchards, 20 isolates were tested, although the range was from eight to 30 isolates.

The number of QoI fungicides applied in the apple blocks sampled in the orchard survey was determined from the Pipfruit New Zealand spray diary database. Numbers of applications of products containing trifloxystrobin, kresoximmethyl or pyraclostrobin were summarised for five seasons (2007-2008, 2008-2009, 2009-2010 and 2010-2011 and for the 2011-12 season up to the time the $V$. inaequalis samples were taken). Four of the five organic orchards (HB-05, HB-07, HB-08, HB-15) had received no QoI fungicides for at least 5 years, but organic orchard HB-06, which had been under organic management for only 3 years, had received synthetic fungicides other than QoIs before that.

\section{RESULTS}

Mycelial growth assay and PCR test development Growth inhibition by trifloxystrobin for the 12 $V$. inaequalis isolates tested using the mycelial growth assay was greater and more consistent in the presence of SHAM than in the absence of SHAM and therefore $\mathrm{EC}_{50}$ values in the presence of SHAM are presented. Isolates that were resistant to trifloxystrobin were clearly distinguished from those that were sensitive, although isolate 9-9 had a higher $\mathrm{EC}_{50}$ value than the other sensitive isolates (Table 1). The resistant isolates were not inhibited by even the highest trifloxystrobin concentration of $100 \mathrm{mg} /$ litre (Figure 1). All four isolates from organic orchards were sensitive and six out of the eight isolates from the high-QoI use orchards were resistant.

The PCR-based test gave clear results, with isolates 4-4, 8-7, 8-11 and 9-10 showing positive $\sim 500$ bp bands for the G143A mutation (Figure 2 ). Presence or absence of the gene mutation agreed completely with the detection of resistance by $\mathrm{EC}_{50}$ on agar for the nine isolates tested by both methods (Table 1). Amplification of the $\sim 300$ bp internal control DNA fragment from exon 7 of the cytochrome $b$ gene was weak 


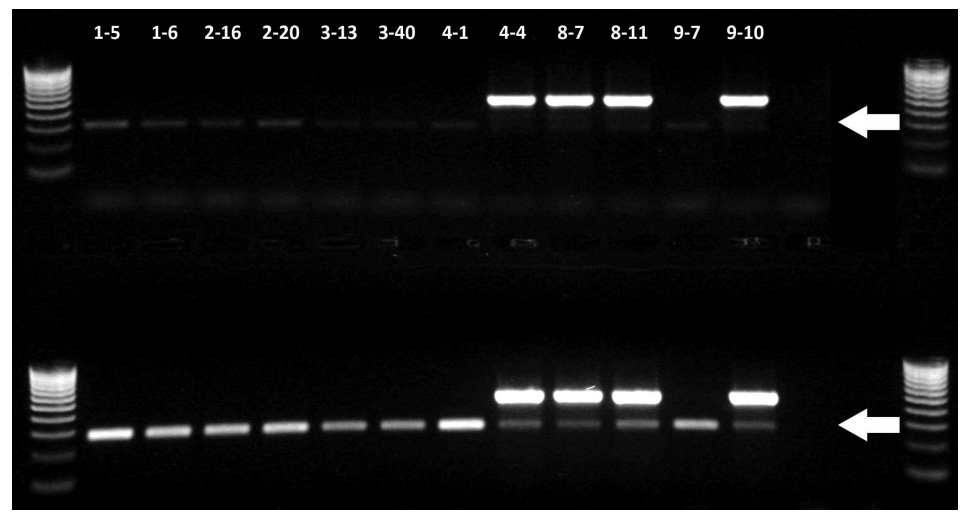

Figure 2 Results of amplification for the Venturia inaequalis cytochrome $b$ gene G143A mutation. Isolate numbers are shown at the top of the gel. Top panel shows results of 30 amplification cycles while the bottom panel is from 35 cycles. Positive amplification of the 500 bp cytochrome $b$ gene fragment, indicating the presence of the G143A mutation, was obtained from Venturia inaequalis isolates 4-4, 8-7, 8-11 and 9-10. The lower $\sim 300 \mathrm{bp}$ fragments (shown by arrows) are from the positive control fragment of the cytochrome $b$ gene, using primers of Fontaine et al. (2009) prior to modification.

Table 1 Fifteen isolates of Venturia inaequalis from organic (no quinone outside inhibitor (QoI) fungicides used) or integrated fruit production (IFP; high QoI use) orchards tested for sensitivity to trifloxystrobin by mycelial growth assay and/or for presence of the G143A mutation associated with resistance to QoI fungicides. $\mathrm{EC}_{50}$ is the effective concentration of trifloxystrobin that inhibited growth by $50 \%$. Salicylhydroxamic acid (SHAM; $100 \mathrm{mg} /$ litre) was included in the agar tests to inhibit the alternative respiration pathway.

\begin{tabular}{lcccc}
\hline & & & & $\mathrm{S}=$ sensitive \\
Orchard type & Isolate no. & $\mathrm{EC}_{50}(\mathrm{mg} /$ litre $)$ & G143A mutation & $\mathrm{R}=$ resistant \\
\hline Organic & $1-5^{1}$ & 0.015 & Absent & $\mathrm{S}$ \\
Organic & $1-6^{1}$ & $3-$ & Absent & $\mathrm{S}$ \\
Organic & $2-16$ & - & Absent & $\mathrm{S}$ \\
Organic & $2-20^{1}$ & 0.018 & Absent & $\mathrm{S}$ \\
Organic & $3-13$ & 0.021 & Absent & $\mathrm{S}$ \\
Organic & $3-40^{1}$ & 0.013 & Absent & $\mathrm{S}$ \\
IFP & $4-1$ & - & Absent & $\mathrm{S}$ \\
IFP & $4-4$ & $>100$ & Present & $\mathrm{R}$ \\
IFP & $4-9^{2}$ & $>100$ & - & $\mathrm{R}$ \\
IFP & $8-5$ & $>100$ & - & $\mathrm{R}$ \\
IFP & $8-7^{2}$ & $>100$ & Present & $\mathrm{R}$ \\
IFP & $8-11^{2}$ & $>100$ & Present & $\mathrm{R}$ \\
IFP & $9-7^{1}$ & 0.06 & Absent & $\mathrm{S}$ \\
IFP & $9-9$ & 0.134 & - & $\mathrm{S}$ \\
IFP & $9-10^{2}$ & $>100$ & Present & $\mathrm{R}$ \\
\hline
\end{tabular}

${ }^{1} \mathrm{~S}$ and ${ }^{2} \mathrm{R}$ isolates used in the plant inoculation assay.

${ }^{3}$ Not tested. 


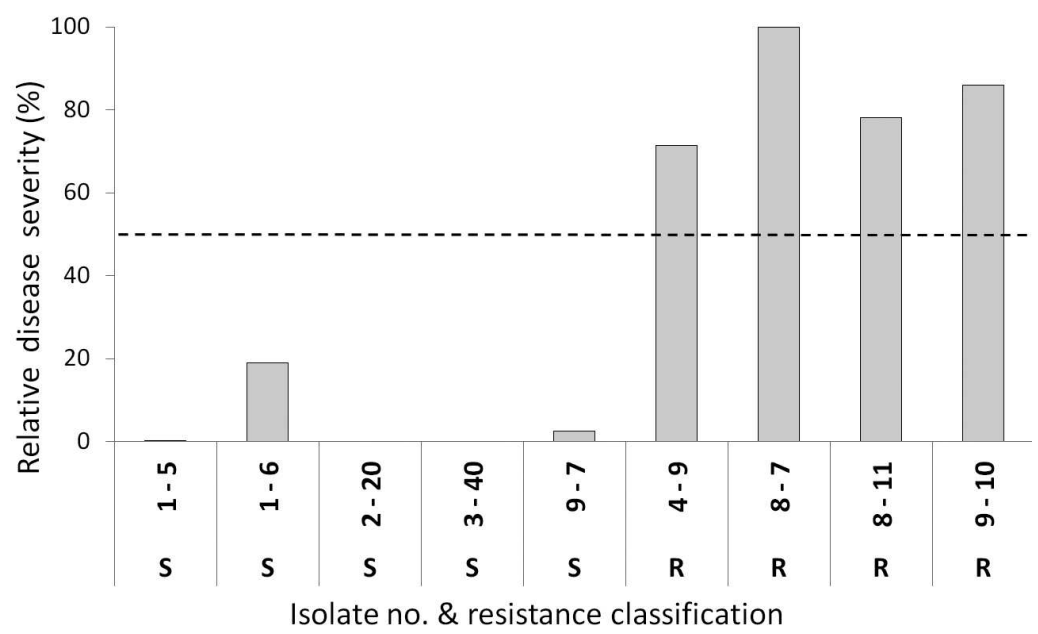

Figure 3 Relative disease severity as the mean severity (percentage leaf area with sporulating Venturia inaequalis) on trifloxystrobin-treated apple leaves as a percentage of severity on water-sprayed leaves. Potted apple trees were treated with trifloxystrobin, then inoculated with isolates of $V$. inaequalis that were classified as either sensitive $(\mathrm{S})$ or resistant $(\mathrm{R})$ to trifloxystrobin according to mycelial growth assay and presence of the G143A mutation. The dashed line indicates a threshold of 50\% mean severity, above which isolates were considered resistant in the plant assay.

after 30 cycles but was improved after 35 cycles (Fontaine et al. 2009).

\section{In vivo sensitivity tests on potted apple trees}

There were clear differences in relative black spot severity between leaves treated with trifloxystrobin then inoculated with either $\mathrm{R}$ or $\mathrm{S}$ isolates and those treated with water then inoculated. For the non-fungicide-treated leaves, mean percentage severity was not significantly different $(\mathrm{P}>0.05)$ between leaves inoculated with $\mathrm{S}$ and $\mathrm{R}$ isolates, indicating that both were equally able to cause disease. Relative severity on the trifloxystrobin-treated trees inoculated with the $\mathrm{S}$ isolates was low, although not always zero (Figure 3). A threshold of 50\% relative severity clearly differentiated between $\mathrm{S}$ and $\mathrm{R}$ isolates and the differences agreed with the $\mathrm{EC}_{50}$ and PCR results (Table 1). In a preliminary plant inoculation experiment using a mixture of four $\mathrm{R}$ isolates carrying the G143A mutation and a mixture of four S isolates without the G143A mutation, there was the same clear result after treatment with trifloxystrobin of complete control of the $\mathrm{S}$ isolates and no control of the $\mathrm{R}$ isolates (data not presented).

\section{Orchard sampling, V. inaequalis isolation in 2011-12 and G143A testing}

Of all the isolates tested, $54 \%$ had the mutation for resistance to QoIs. In Hawke's Bay orchards, the percentage of isolates with the G143A mutation ranged from 5 to $100 \%$. Frequency of the mutation in the five Hawke's Bay organic orchards (HB-05, HB-06, HB-07, HB-08, HB-15) varied from 5 to $45 \%$. The Waikato orchards had mutation rates of $0-26 \%$, Nelson orchards 13 $80 \%$, and Otago orchards 75-100\% (Figure 4).

\section{Resistance in relation to fungicide use}

There was broad agreement between G143A mutation frequency and overall use of QoI fungicides. The organic orchards, with no recent QoI use, had the lowest G143A frequency and some of the Hawke's Bay orchards with the highest QoI use had the highest G143A 
frequency (Figure 5). However, over all orchards individually, the relationship between frequency of G143A mutation detection and mean number of QoI applications per orchard, although significant $(\mathrm{P}=0.003)$ was weak $\left(\mathrm{R}^{2}=0.2\right)$. The low G143A mutation frequency in Waikato was not associated with low QoI use (Figure 5).

\section{DISCUSSION}

Following the first detection of the G143A mutation in New Zealand $V$. inaequalis samples during 2009, an agar plate assay for QoI sensitivity and a PCR test for the $V$. inaequalis G143A mutation sequence were successfully optimised. From nine 2010-11 V. inaequalis samples, there was complete agreement between the mycelial growth assay and the presence/absence of the G143A sequence. It is acknowledged that there may be other QoI-associated mutations found in New Zealand $V$. inaequalis, but based on these initial results and overseas studies, it seems reasonable to assume that this mutation is the dominant cause of resistance here. Although a range of mutations has been reported, in other countries the G143A sequence change is the most commonly detected QoI-related mutation, including in $V$. inaequalis (Fungicide Resistance Action Committee 2013; Gisi et al. 2002). Other mutations in New Zealand could be detected by gene sequencing, but the cost of this approach does not seem worthwhile in the absence of discordance between G143A mutation PCR assay and field resistance. The clear differentiation between resistant and sensitive isolates is typical for fungicides that have a site specific mode of action and where the resistance is monogenic. The proportion of resistant isolates can increase rapidly after QoI applications. For example, in Mycosphaerella graminicola, resistant ascospore populations increased from 35 to $80 \%$ in wheat plots after the first QoI application and exceeded 90\% after the second QoI application (Fraaije et al. 2005). This pattern is quite different from that observed with the DMI fungicides, where there is a continuous range of sensitivities and mean $\mathrm{EC}_{50}$ shifts gradually towards resistance over a long period of time (Beresford et al. 2013).

From the results of both methods combined, all six isolates from organic orchards were sensitive, and six out of nine of the isolates from high QoI use orchards were resistant. The PCR test was therefore used to test the larger number of isolates from the nationwide survey. The survey of 41 orchards in Hawke's Bay, Waikato, Nelson and Otago showed a trend of resistance to QoIs in these regions. Of the 802 isolates tested, 54\% had the G143A mutation for resistance to QoIs present and 59\% of orchards had more than $50 \%$ of isolates carrying the resistance mutation.

The G143A mutation was present in all regions but was less frequent in Waikato orchards, where it occurred in only $6 \%$ of 117 isolates tested and no orchards had $>50 \%$ of isolates with the mutation. None of the organic orchards examined was organic prior to the introduction of QoI fungicides into New Zealand in the late 1990s. The organic orchard HB-05, which had the lowest presence of the G143A mutation ( $5 \%$ of 20 isolates tested), was in a remote area and had been organic for 12 years. Nevertheless, the G143A mutation was present. The organic orchard HB-06 had been organic for 3 years but had never received QoI fungicides. However, this orchard still had a $22 \%$ presence of the G143A mutation. The organic orchard HB-08 had a high mutation rate $(45 \%)$ and had not received QoI fungicides for at least 5 years. Michalecka et al. (2011) also found high (46\%) levels of the G143A mutation in one organic orchard in Poland. The widespread distribution of QoI resistance in New Zealand, including organic orchards, may reflect mobility in the $V$. inaequalis population. Movement of the pathogen may occur through aerial spread of ascospores or through passage of infected budwood and plant material between orchards and nurseries. Ascospores have been indicated to be important in the spread of the G143A mutation in field populations of M. graminicola (Fraaije et al. 2005). Furthermore, it may also reflect de novo development of resistance in multiple areas as a result of selection through QoI fungicide use. Other factors that affect occurrence of resistance are disease pressure and fitness of resistant phenotypes (Leadbeater 2012). The plant inoculation study suggested that isolates carrying the G143A mutation were as fit, 


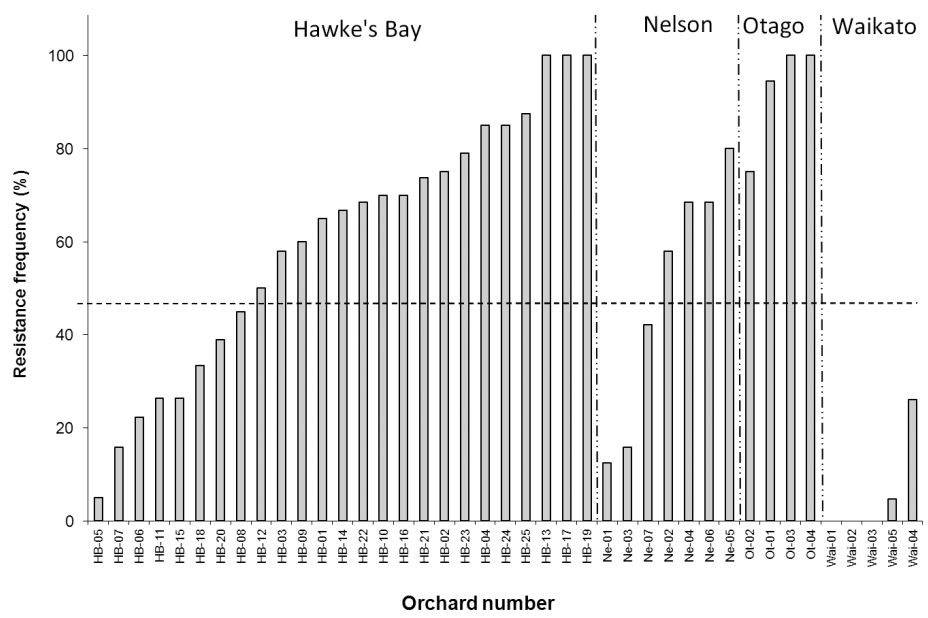

Figure 4 Frequency of isolates per orchard with the G143A mutation, which confers QoI resistance, within each region. The organic orchards were HB-05, HB-06, HB-07, HB-08 and HB-15.

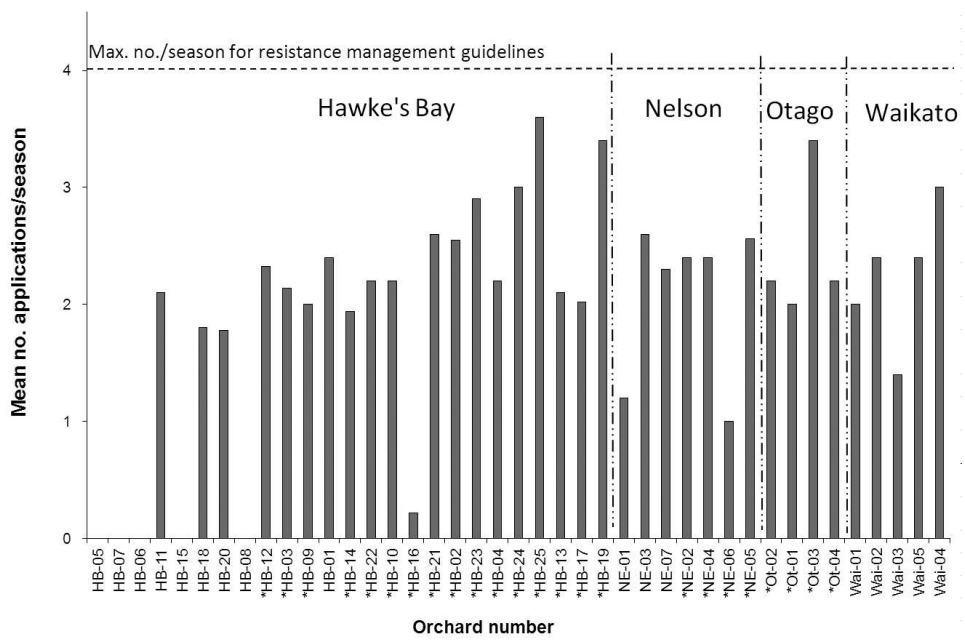

Figure 5 Fungicide use, as mean number of quinone outside inhibitor (QoI) applications per season over five seasons, for 41 orchards in the 2011-12 resistance survey. Orchards are ranked by frequency of isolates with the G143A mutation, which confers QoI resistance, within each region. Orchards where more than $50 \%$ of isolates tested had the G143A mutation are marked with an asterisk.

in terms of their ability to cause disease, as those not carrying the mutation.

The plant inoculation study also showed that disease control by the QoI fungicide trifloxystrobin was compromised for all the isolates containing the G143A mutation. This suggests that orchards with a high G143A mutation frequency can be expected to experience loss of black spot control where QoI fungicides are relied upon.
The knowledge gained from this study about the widespread resistance of $V$. inaequalis to QoI fungicides in New Zealand orchards will be used to advise the apple industry about the ongoing usefulness of QoI fungicides and to develop new QoI resistance management guidelines. In conjunction with this, the DNAbased method can now be further developed to extract DNA directly from lesions on apple leaves, eliminating the time-consuming step of 
isolating single-spore cultures from leaves onto agar plates. This type of testing will provide a rapid method for determining QoI resistance frequency in individual orchards.

\section{ACKNOWLEDGEMENTS}

We thank Pipfruit New Zealand Inc. and The New Zealand Institute for Plant \& Food Research Limited for funding this project, and orchardists in Hawke's Bay, Waikato, Nelson and Otago who allowed black spot sampling in their orchards. BASF New Zealand Ltd and Bayer CropScience assisted with the PCR detection method development. We also thank Dr Mike Butcher of Pipfruit New Zealand Inc. for reviewing a draft of this paper, Ngaire Larsen for assistance with culturing $V$. inaequalis and Matt Templeton for providing the modified DNA extraction method.

\section{REFERENCES}

Beresford RM, Wright, PJ, Wood PN, Park NM 2012. Sensitivity of Venturia inaequalis to myclobutanil, penconazole and dodine in relation to fungicide use in Hawke's Bay apple orchards. New Zealand Plant Protection 65: 106-113.

Beresford RM, Wright PJ, Wood PN, Park NM, Larsen NJ, Fisher BM 2013. Resistance of Venturia inaequalis to demethylation inhibitor and dodine fungicides in four New Zealand apple-growing regions. New Zealand Plant Protection 66: 274-283.

Chapman K, Sundin GW, Beckerman JL 2011. Identification of resistance to multiple fungicides in field populations of Venturia inaequalis. Plant Disease 95: 921-926.

Fungicide Resistance Action Committee 2010. QoI working group - 2010 minutes. http://www.frac.info/work/work_qolf.htm (accessed 10 May 2013).

Fungicide Resistance Action Committee. 2013. List of pathogens with field resistance towards QoI fungicides (updated 6/12/12) http:// www.frac.info/work/Species\%20with $\% 20$ QoI-resistance\%20(Status\%20Dec.\%20 2012)l.pdf (accessed 19 April 2013).
Fontaine S, Remuson F, Fraissinet-Tachet L, Micoud A, Marmeisse R, Melyah D 2009. Monitoring of Venturia inaequalis harbouring the QoI resistance G143A mutation in French orchards as revealed by PCR assays. Pest Management Science 65: 74-81.

Fraaije BA, Cools HJ, Fountaine J, Lovell DJ, Motteram J, West JS, Lucas JA 2005. Role of ascospores in further spread of QoIresistant cytochrome $b$ alleles (G143A) in field populations of Mycosphaerella graminicola. Phytopathology 95: 933-941.

Gisi U, Sierotzki H, Cook A, McCaffery A 2002. Mechanisms influencing the evolution of resistance to QoI inhibitor fungicides. Pest Management Science 58: 859-867.

Jobin T, Carisse O 2007. Incidence of myclobutaniland kresoxim-methyl-insensitive isolates of Venturia inaequalis in Quebec orchards. Plant Disease 91: 1351-1358.

Köller W, Parker DM, Turechek WW, AvilaAdame C, Cronshaw K 2004. A two-phase resistance response of Venturia inaequalis to the QoI fungicides kresoxim-methyl and trifloxystrobin. Plant Disease 88: 537-544.

Küng Farber R, Chin M, Leadbitter N 2002. Sensitivity of Venturia inaequalis to trifloxystrobin. Pest Management Science 58: 261-267.

Leadbeater A 2012. Resistance risk to QoI fungicides and anti-resistance strategies. In: Thind TS ed. Fungicide resistance in plant protection: risk and management. CSB International, Wallingford, UK. Pp. 141-154.

Michalecka M, Malinowski T, Broniarek-Niemiec A, Bielenin A 2011. Real-time PCR assay with SNP-specific primers for the detection of a G143A mutation level in Venturia inaequalis field populations. Journal of Phytopathology 159: 569-578.

Möller EM, Bahnweg G, Sandermann, H, Geiger $\mathrm{HH}$ 1992. A simple and efficient protocol for isolation of high molecular weight DNA from filamentous fungi, fruit bodies and infected plant tissues. Nucleic Acids Research. 20: 6115-6116.

Steinfeld U, Sierotzki H, Parisi S, Poirey S, Gisi U 2001. Sensitivity of mitochondrial respiration to different inhibitors in Venturia inaequalis. Pest Management Science 57: 787-796. 